\title{
Article \\ Cost-Effectiveness of Screening Algorithms for Familial Hypercholesterolaemia in Primary Care
}

\author{
Matthew Jones ${ }^{1, *(D)}$, Ralph K. Akyea ${ }^{1} \mathbb{D}$, Katherine Payne ${ }^{2} \mathbb{D}$, Steve E. Humphries ${ }^{3}$, Hasidah Abdul-Hamid ${ }^{1,4}$, \\ Stephen Weng ${ }^{1}$ and Nadeem Qureshi ${ }^{1}$ (D)
}

1 NIHR School for Primary Care Research, University of Nottingham, Nottingham NG7 2UH, UK; ralph.akyea1@nottingham.ac.uk (R.K.A.); hasidah.abdulhamid@nottingham.ac.uk or hasidah@uitm.edu.my (H.A.-H.); stephen.weng@evda.co.uk (S.W.); nadeem.qureshi@nottingham.ac.uk (N.Q.)

2 Manchester Centre for Health Economics, School of Health Sciences, The University of Manchester, Manchester M13 9PL, UK; katherine.payne@manchester.ac.uk

3 Institute of Cardiovascular Science, University College London, London WC1E 6HX, UK; steve.humphries@ucl.ac.uk

4 Department of Primary Care Medicine, Faculty of Medicine, Jalan Hospital, Universiti Teknologi MARA, Sungai Buloh 47000, Malaysia

* Correspondence: matthew.jones3@nottingham.ac.uk; Tel.: +44-115-74-86710

check for updates

Citation: Jones, M.; Akyea, R.K.;

Payne, K.; Humphries, S.E.;

Abdul-Hamid, H.; Weng, S.; Qureshi,

N. Cost-Effectiveness of Screening

Algorithms for Familial

Hypercholesterolaemia in Primary

Care. J. Pers. Med. 2022, 12, 330.

https://doi.org/10.3390/jpm

12030330

Academic Editor: Kathryn A. Phillips

Received: 14 December 2021

Accepted: 18 February 2022

Published: 22 February 2022

Publisher's Note: MDPI stays neutral with regard to jurisdictional claims in published maps and institutional affiliations.

Copyright: () 2022 by the authors Licensee MDPI, Basel, Switzerland. This article is an open access article distributed under the terms and conditions of the Creative Commons Attribution (CC BY) license (https:// creativecommons.org/licenses/by/ $4.0 /)$.

\begin{abstract}
Although familial hypercholesterolemia (FH) screening within primary care is considered cost-effective, which screening approach is cost-effective has not been established. This study determines the cost-effectiveness of six case-finding strategies for screening of electronic health records to identify index patients who have genetically confirmed monogenic FH in English primary care. A decision tree was constructed to represent pathways of care for each approach (FH Case Identification Tool (FAMCAT) versions 1 and 2, cholesterol screening, Dutch Lipid Clinic Network (DLCN), Simon Broome criteria, no active screening). Clinical effectiveness was measured as the number of monogenic FH cases identified. Healthcare costs for each algorithm were evaluated from an NHS England perspective over a 12 week time horizon. The primary outcome was the incremental cost per additional monogenic FH case identified (ICER). FAMCAT2 was found to dominate (cheaper and more effective) cholesterol and FAMCAT1 algorithms, and extendedly dominate DLCN. The ICER for FAMCAT2 vs. no active screening was 8111 GBP (95\% CI: 4088 to 14,865), and for Simon Broome vs. FAMCAT2 was 74,059 GBP $(95 \%$ CI: $-1,113,172$ to 1,697,142). Simon Broome found the largest number of $\mathrm{FH}$ cases yet required 102 genetic tests to identify one FH patient. FAMCAT2 identified fewer, but only required 23 genetic tests.
\end{abstract}

Keywords: economic evaluation; cost-effectiveness; genetics; electronic health records; familial hypercholesterolemia

\section{Introduction}

Familial hypercholesterolaemia (FH) is an autosomal dominant disorder, caused by carrying a mutation in any of four genes ( $L D L R / A P O B / P C S K 9 / A P O E)$ [1]. Individuals with $\mathrm{FH}$ have elevated blood concentrations of low-density lipoprotein cholesterol (LDL-C) since birth and, if untreated, are at higher risk of developing early cardiovascular disease than the normal population [2,3]. Treatment with high-intensity statins is recommended by NICE (CG71) [4] and has been shown to substantially reduce both morbidity [5] and mortality [6]. In the UK, around one in 250 individuals are thought to have FH [7], of whom fewer than $10 \%$ have currently been identified [8].

Decision making in various countries requires that new healthcare technologies demonstrate value for money [9]. While screening for FH within primary care has been demonstrated to be cost-effective [10], there are varying approaches with little evidence as to 
which offers best value for money [4,11]. Furthermore, there has been recent development of various algorithms which can screen a patient's electronic health record (EHR) and assess their risk of having $\mathrm{FH}[12]$.

The aim of this study was to determine the cost-effectiveness of five approaches for the systematic screening of EHRs to identify index patients who have genetically confirmed monogenic FH registered to typical English primary care practice, compared with no active screening of EHRs.

\section{Materials and Methods}

An early decision-analytic model was conceptualised and built to address the decision problem (see Supplementary Table S1) following published recommendations [13-15], and reported in line with published criteria [16].

\subsection{Population}

A typical primary care practice in NHS England would have approximately 10,000 patients registered, with 4500 patients having a cholesterol measurement recorded and being eligible for screening of EHR to detect possible FH. The hypothetical cohort was 4500 adult patients, with a mean age of 56 years. This profile of patients represents those who took part in the FH Case Identification Tool (FAMCAT) feasibility study [17], funded by the National Institute of Health Research (NIHR) School for Primary Care Research (Grant SPCR 332).

\subsection{Interventions and Comparator}

Table 1 describes the five interventions potentially possible given the availability of algorithms and case-finding criteria that can be used to guide how to screen the EHR of patients in primary care. The comparator was chosen because, although screening within primary care is recommended [4], expert consensus from six clinical members of the FAMCAT feasibility study steering committee suggested that there is little evidence that any form of FH screening is actually carried out in primary care. Three case-finding criteria were selected because they represent the current recommended approaches across several countries (cholesterol, Dutch Lipid Clinic Network (DLCN), and Simon Broome (SB)) [4,18], along with two newly developed algorithms which have demonstrated increased sensitivity and specificity from database studies (FAMCAT 1 and 2) [12,19].

\subsection{Study Design}

We determined the possible patient pathways using expert consensus, formed from eight clinical members of the FAMCAT feasibility study steering committee. A decision tree was selected as the most appropriate decision analytic model for the selected time horizon of the evaluation [20]. It was recommended by clinical experts that the focus should be on three types of patients: those with a positive monogenic FH mutation, those with a variant of unknown significance (VUS), and those with no relevant mutation. The model's first stage split the three types of patients before engaging with the primary care (see nodes A and $C$ in Figure 1), and then determined whether the patient has fulfilled the diagnostic criteria or not (see nodes B, D, and E in Figure 1).

For patients in the comparator arm, as no screening was conducted, the pathway involved no primary care involvement. The initial pathway for all the other interventions was initial screening of electronic health record, requesting the family history questionnaire and updating the electronic health record, and finally secondary screening of electronic record. For those who did not fulfil the diagnostic criteria for the interventions, it was assumed that they would receive no further treatment. Patients who fulfil the diagnostic criteria are invited to primary care to take a blood sample for genetic testing, with the genetic test done at a secondary care facility. Once the patient's general practitioner (GP) received the result of the genetic test, if a patient was found to have a FH mutation or a VUS, then the patient was required to attend a double consultation with their GP to inform 
them of their results. If the genetic test detected no relevant mutation, then the patient was informed of the result via a letter from their GP.

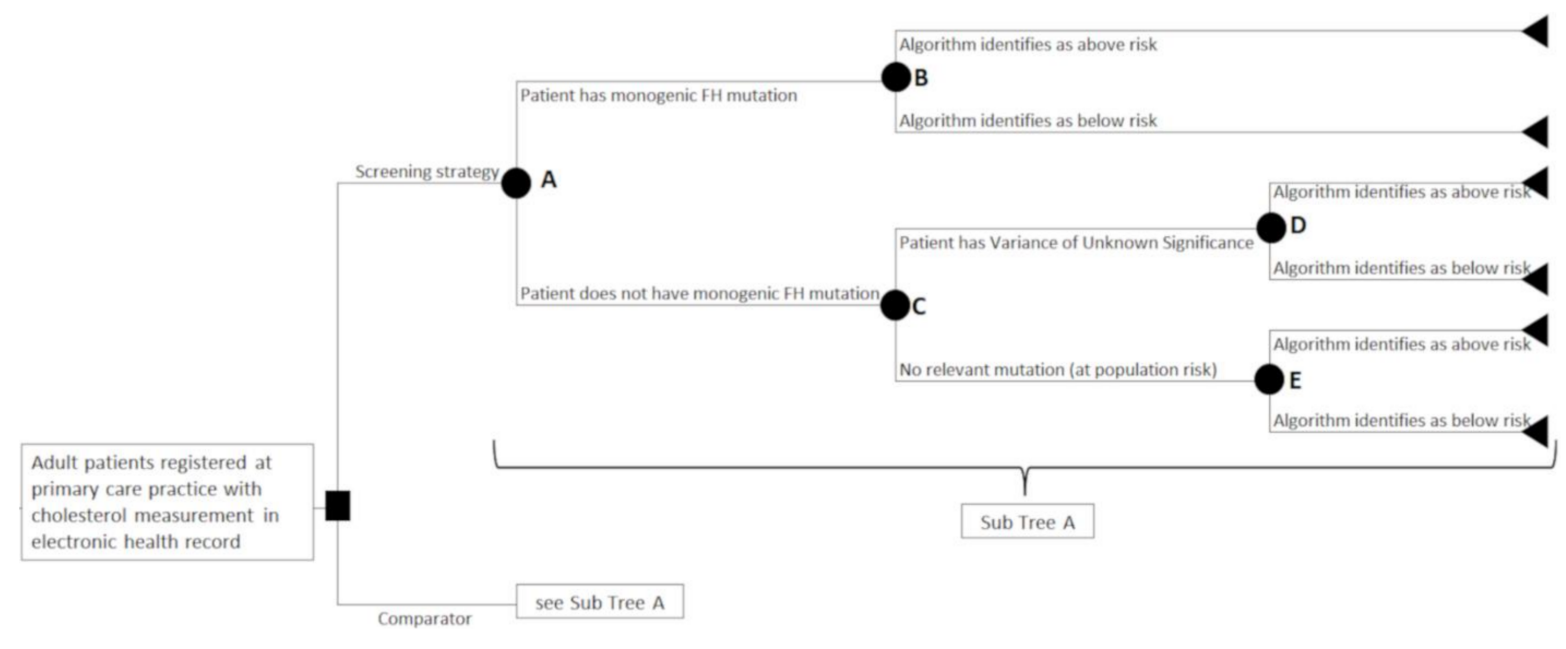

Figure 1. Decision tree structure for all interventions, with squares denoting decision nodes, circles denoting chance nodes, and triangles representing the end of the tree.

Table 1. Description of interventions and comparator.

\begin{tabular}{|c|c|c|}
\hline Name of Intervention & Action & Requirements to Run Case-Finding Criteria \\
\hline $\begin{array}{c}\text { No active, systematic screening of electronic } \\
\text { health records }\end{array}$ & $\begin{array}{l}\text { Patient electronic health records are not screened for } \\
\text { possible markers of FH }\end{array}$ & None \\
\hline Cholesterol ${ }^{1}[4]$ & $\begin{array}{l}\text { Search electronic health records for individuals who } \\
\text { are either (i) younger than } 30 \text { years old with a total } \\
\text { cholesterol concentration greater than } 7.5 \mathrm{mmol} / \mathrm{L} \text {, } \\
\text { or (ii) } 30 \text { years or older with a total cholesterol } \\
\text { concentration greater than } 9.0 \mathrm{mmol} / \mathrm{L} \text {. Current } \\
\text { approach as recommended by NICE [4] }\end{array}$ & Most recent LDL-cholesterol concentration level \\
\hline Dutch Lipid Clinic Network ${ }^{1}[4]$ & $\begin{array}{l}\text { Points-based criteria. Points awarded on the basis of } \\
\text { symptoms, cholesterol levels, family history of } \\
\text { illness, and/or DNA test. Patients are scored, with a } \\
\text { score of eight or greater having definite FH, and a } \\
\text { score of five or greater as possible FH. }\end{array}$ & $\begin{array}{l}\text { Untreated LCL-C recorded, family history of } \\
\text { premature coronary and/or vascular disease, } \\
\text { first-degree relative with known LDL-cholesterol } \\
\text { above 95th percentile, tendinous xanthomata and/or } \\
\text { arcus cornealis, clinical history of premature } \\
\text { coronary artery disease, cerebral, or peripheral } \\
\text { vascular disease }\end{array}$ \\
\hline Simon Broome Criteria ${ }^{1}[4]$ & $\begin{array}{l}\text { Category-based criteria based on a patient's } \\
\text { cholesterol levels, family history of premature CHD } \\
\text { or high cholesterol, and/or DNA test. Patients are } \\
\text { either coded as definite or probable FH. }\end{array}$ & $\begin{array}{l}\text { Age, total cholesterol, LDL cholesterol, tendon } \\
\text { xanthomas in patient, first- or second-degree } \\
\text { relative, DNA-based evidence of a functional LDLR, } \\
\text { PCSK9, and APOB mutation, family history of } \\
\text { premature CVD events, family history of extremely } \\
\text { high cholesterol. }\end{array}$ \\
\hline $\begin{array}{l}\text { Familial Hypercholesterolaemia Case Identification } \\
\text { Tool version } 1 \text { (FAMCAT1) }{ }^{1}[12]\end{array}$ & $\begin{array}{c}\text { A multivariate logistic regression model, consisting } \\
\text { of nine diagnostic indicators stratified by gender. } \\
\text { Age, cholesterol levels, and triglycerides are } \\
\text { categorised. Algorithm identifies patients at } \\
\text { increased risk of FH. }\end{array}$ & $\begin{array}{l}\text { Gender, total cholesterol or LDL-cholesterol, age } \\
\text { during cholesterol measurement, triglycerides, } \\
\text { lipid-lowering drug usage, family history of FH, } \\
\text { family history of CHD, family history of raised } \\
\text { cholesterol, diabetes, and chronic kidney disease. }\end{array}$ \\
\hline $\begin{array}{l}\text { Familial Hypercholesterolaemia Case Identification } \\
\text { Tool version } 2 \text { (FAMCAT2) }{ }^{1}[12]\end{array}$ & $\begin{array}{c}\text { An updated FAMCAT1 algorithm, with re-estimated } \\
\text { regression equations using continuous variables for } \\
\text { total cholesterol, LDL-cholesterol, triglycerides, and } \\
\text { age. Algorithm identifies patients at increased risk } \\
\text { of FH. }\end{array}$ & As above \\
\hline
\end{tabular}

\footnotetext{
${ }^{1}$ Requires a search of electronic health records.
}

\subsection{Model Inputs}

The decision tree required three types of model inputs: probabilities, costs, and outcomes (see Supplementary Table S2). According to the estimates used for the proportions, in the cohort of 4500 adult patients eligible for screening, 16 would have monogenic $\mathrm{FH}$, nine would have a VUS, and the remaining 4475 would have no relevant mutation. 


\subsection{Costs}

As the pathway for the comparator assumed no contact with primary care services, the cost per patient was 0 GBP. For the intervention pathway, healthcare resource use was based on estimates from the FAMCAT feasibility study. The intervention pathways were split into three parts, and the total costs per patient for each part of the pathway can be found in Table S2. For the first part of the intervention pathways, resource use included practice administrative time for performing EHR searches, letter preparation, posting, and entering the family history questionnaire, as well as time spent by the GP on reviewing the results of the searches. Resource use for the first part was estimated across all study practices, so the per patient cost was estimated by dividing the total cost for the searches by number of eligible patients registered (86,219 patients).

For the second part of the intervention pathways, resource use focused on performing blood tests within primary care, posting samples, and analysing samples for the genetic test in secondary care. These resources were only used by patients who fulfilled the diagnostic criteria and were applied on a per patient level. For the third part of the intervention pathways, resource use included posting letters to patients, and, for those who had a FH mutation or VUS, a double consultation to discuss the genetic test results with their GP.

\subsection{Analytical Strategy}

We used the standard method for evaluating multiple technologies [21], details of which can be found in Table S1.

\subsection{Sensitivity Analyses}

A probabilistic sensitivity analysis (PSA) whereby all model inputs could vary simultaneously was performed via 1000 Monte Carlo simulations using standard techniques [22], details of which can be found in Table S2. Information on uncertainty was taken from the literature, using the FAMCAT feasibility study data by estimating Wilson 95\% confidence intervals (CI) [23], or assuming a standard error of $10 \%$ of the mean value if no information was identified [22]. Results of the PSA were plotted as scatterplots on the incremental cost-effectiveness plane and cost-effectiveness acceptability curves (CEACs) for each intervention. A one-way sensitivity analysis was performed on the proportion of patients with no relevant mutation being identified as above risk (Node E in Figure 1), with values varied between zero and twice the mean value for each of the algorithms simultaneously, in $10 \%$ increments. Two scenario analyses were performed on the diagnostic thresholds for the FAMCAT1 and FAMCAT2 algorithms, simultaneously changing the proportion of patients identified by each algorithm for nodes B, D, and E (see Table S3). A final scenario analysis was performed on the proportion of patients with VUS within the cohort, using a value of three in 100 for the proportion of patients with monogenic FH [24].

\subsection{Patient and Public Involvement}

Patient representatives participated in developing the model and interpreting the study results.

\section{Results}

Estimated expected costs and outcomes are reported in Table 2. After ranking the interventions by cost, the incremental analysis suggested that FAMCAT2 dominated FAMCAT1 and cholesterol, while extendedly dominating DLCN. This was because FAMCAT2 required the fewest number of genetic tests to identify one monogenic $\mathrm{FH}$ case, with the cost of the genetic test being the largest component of the costs of the different interventions. However, FAMCAT2 did not dominate SB, since SB yielded the greatest number of FH cases identified but at a much higher expected total cost per patient. This was because the $\mathrm{SB}$ criteria required a large number of genetic tests to find one monogenic FH case. 
Table 2. Initial findings for the evaluation, with algorithms ranked by expected total cost per patient.

\begin{tabular}{|c|c|c|c|c|c|c|c|}
\hline Intervention & $\begin{array}{l}\text { Expected Total Cost per } \\
\text { Patient (GBP; 2018/2019) }\end{array}$ & $\begin{array}{l}\text { Number of FH } \\
\text { Cases Identified }\end{array}$ & $\begin{array}{l}\text { Number of Genetic Tests } \\
\text { to Fine One FH Case }\end{array}$ & Incremental Cost (GBP) ${ }^{1}$ & $\begin{array}{l}\text { Incremental Number of } \\
\text { FH Cases Identified }\end{array}$ & $\begin{array}{c}\text { Incremental Cost per } \\
\text { Additional FH Case } \\
\text { Identified (GBP; } \\
\text { 2018/2019) }\end{array}$ & Notes \\
\hline No active screening & $£ 0$ & 0 & - & - & - & - & \\
\hline Dutch Lipid & $£ 16.12$ & 6 & 35 & 16.12 & 6.18 & 11,734 & $\begin{array}{l}\text { Versus no active screening, } \\
\text { extendedly dominated }{ }^{3} \\
\text { by FAMCAT } 2\end{array}$ \\
\hline FAMCAT1 & $£ 18.51$ & 5 & 49 & 2.39 & -1.03 & Dominated $^{2}$ & Dominated by Dutch Lipid \\
\hline FAMCAT2 & $£ 19.02$ & 11 & 23 & 19.02 & 11.33 & 7552 & Versus no active screening \\
\hline Cholesterol & $£ 23.63$ & 7 & 46 & 4.61 & -4.12 & Dominated $^{2}$ & Dominated by FAMCAT2 \\
\hline Simon Broome & $£ 87.28$ & 13 & 102 & 68.26 & 1.49 & 206,431 & Versus FAMCAT 2 \\
\hline
\end{tabular}

${ }^{1}$ Defined as expected total cost per patient for intervention minus expected total cost per patient for comparator. ${ }^{2}$ Occurs when an intervention is more expensive and less effective than the comparator. ${ }^{3}$ Occurs when the ICER is higher than the next more effective alternative. 


\subsection{Probabilistic Sensitivity Analysis}

PSA results can be found in Table 3, while the scatterplot for the incremental analysis can be found in Figure 2A. The PSA supported the initial findings, and there was no change in the ranking of the interventions, with FAMCAT2 appearing to dominate FAMCAT1 and cholesterol screening, and extendedly dominating DLCN. However, the finding was nonsignificant as the $95 \%$ CI for incremental FH cases identified crossed zero, implying there were scenarios where DLCN, FAMCAT1, and cholesterol were preferred over FAMCAT2. The CEACs in Figure 2B demonstrated that, at most, FAMCAT1 had a 34\% chance of being preferred to DLCN, while cholesterol had a chance of $24 \%$ of being preferred to FAMCAT2. FAMCAT2 had at least a $30 \%$ chance of being preferred to DLCN, increasing to $97 \%$ chance at a higher willingness to pay per monogenic FH case identified. SB continued not to be dominated, although there were scenarios where it was estimated that SB identified fewer monogenic FH cases than FAMCAT2.

Table 3. Results for the probabilistic sensitivity analysis, with algorithms ranked by mean expected total cost per patient.

\begin{tabular}{|c|c|c|c|c|c|c|}
\hline Screening Algorithm & $\begin{array}{l}\text { Expected Total Cost } \\
\text { per Patient (GBP) } \\
\text { Mean }(95 \% \text { CI) }\end{array}$ & $\begin{array}{l}\text { Number of } \\
\text { FH Cases } \\
\text { Identified } \\
\text { Mean }(95 \% \text { CI) }\end{array}$ & $\begin{array}{l}\text { Number of Genetic } \\
\text { Tests Required to } \\
\text { Identify One Patient } \\
\text { with Monogenic FH } \\
\text { Mean }(95 \% \text { CI) }\end{array}$ & $\begin{array}{c}\text { Incremental Cost } \\
\text { (GBP) } \\
\text { Mean (95\% CI) }\end{array}$ & $\begin{array}{c}\text { Incremental Number } \\
\text { of FH Cases } \\
\text { Identified } \\
\text { Mean }(95 \% \mathrm{CI})\end{array}$ & $\begin{array}{l}\text { Incremental Cost per } \\
\text { Additional FH Case } \\
\text { Identified (GBP) } \\
\text { Mean (95\% CI) }\end{array}$ \\
\hline No active screening & $0(0-0)$ & $0(0-0)$ & $0(0-0)$ & - & - & - \\
\hline Dutch Lipid & $16.32(9.16-25.80)$ & $6(3-11)$ & $40(14-93)$ & $16.32(9.16-25.80)^{1}$ & $6(3-11)^{1}$ & $13,528(5395-31,086)^{1}$ \\
\hline FAMCAT1 & $19.00(10.91-29.02)$ & $5(2-9)$ & $60(22-150)$ & $2.69(-9.30-15.01)^{2}$ & $-1(-6-4)^{2}$ & $2946(-138,736-123,755)^{2}$ \\
\hline FAMCAT2 & $19.23(11.59-28.75)$ & $11(7-17)$ & $24(11-46)$ & $\begin{array}{l}19.23(11.59-28.75)^{1} \\
2.91(-8.91-14.52)^{2}\end{array}$ & $\begin{array}{l}11(7-17)^{1} \\
5(0-10)^{2}\end{array}$ & $\begin{array}{c}8111(4088-14,865)^{1} \\
6118(-22,023-32,018)^{2}\end{array}$ \\
\hline Cholesterol & $23.83(15.37-34.32)$ & $7(4-12)$ & $51(23-103)$ & $4.61(-7.82-17.44)^{3}$ & $-4(-9-1)^{3}$ & $-16,589(-56,929-50,116)^{3}$ \\
\hline Simon Broome & $86.92(70.95-104.80)$ & $13(7-19)$ & $109(66-188)$ & $67.70(48.47-87.22)^{3}$ & $2(-5-7)^{3}$ & $\begin{array}{c}74,059 \\
(-1,113,172-1,697,142)^{3}\end{array}$ \\
\hline
\end{tabular}

${ }^{1}$ Incremental compared to no active screening. ${ }^{2}$ Incremental compared to Dutch Lipid. ${ }^{3}$ Incremental compared to FAMCAT2.

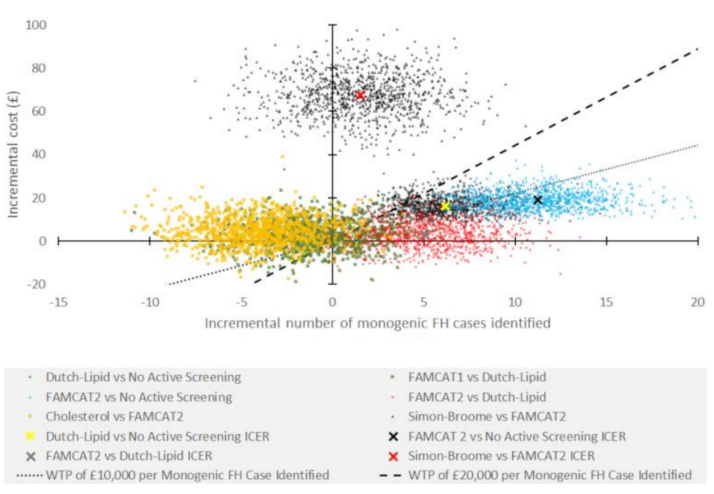

(a)

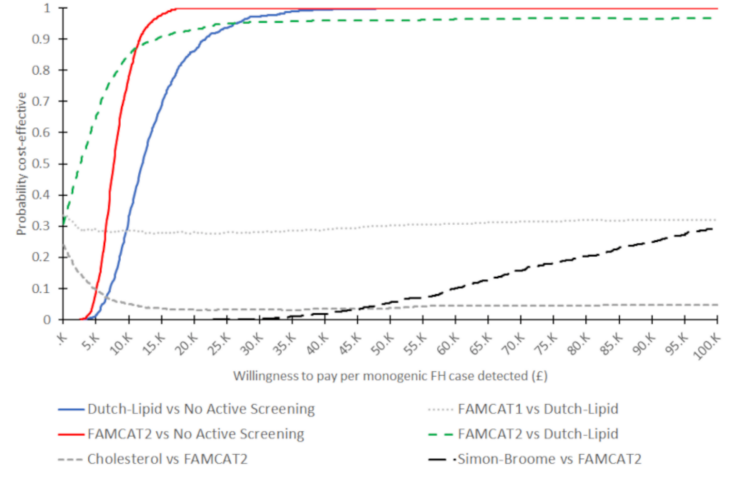

(b)

Figure 2. Results of the probabilistic sensitivity analysis: (a) scatterplot of incremental costs and incremental cases detected on the cost-effectiveness plane for each comparison; (b) cost-effectiveness acceptability curves for each comparison.

\subsection{One-Way Sensitivity Analysis}

Results of the sensitivity analysis for the algorithm identifying a patient with no relevant mutation as above risk can be found in Table S6. Overall results were similar to the initial findings apart from the analysis where the proportion of patients with no relevant mutation being identified as above risk was zero. In that scenario, SB extendedly dominated all other interventions, with an incremental cost-effectiveness ratio (ICER) of 1105 GBP per monogenic FH case identified when compared to no active screening. The analysis demonstrated that the ICER for SB was particularly sensitive to changes in the investigated proportion, while the ICER for FAMCAT2 was less sensitive. 


\subsection{Scenario Analysis}

Findings for the scenario analysis of changing FAMCAT1 and FAMCAT2 thresholds can be found in Table S4. At thresholds of 0.050 or higher, FAMCAT1 was either dominated or extendedly dominated by the FAMCAT2 algorithm or DLCN criteria. For thresholds at or below 0.010, FAMCAT1 was no longer dominated by any intervention and did identify all cases of monogenic FH within the cohort. However, it required a large number of genetic tests to identify one monogenic $\mathrm{FH}$ case and, consequently, was very expensive, with corresponding large ICERs.

At a threshold of 0.002, FAMCAT2 identified most but not all of the FH cases within the cohort, but required a large number of genetic tests and, thus, was very expensive and extendedly dominated by SB. For thresholds between 0.0036 and 0.0047 , the result of the evaluation was similar or identical to the initial findings. At a threshold of 0.010, FAMCAT2 identified $50 \%$ of monogenic $\mathrm{FH}$ cases while only requiring six genetic tests to identify one FH patient, thus having a very low expected cost per patient. At this threshold, the algorithm was dominant over all other interventions except for SB. At a threshold of 0.050 and above, FAMCAT2 now identified very few cases of FH at a very low cost. FAMCAT2 no longer dominated or extendedly dominated any other intervention. In this scenario, the ranking was no active screening, FAMCAT2, DLCN, cholesterol, and SB, with FAMCAT1 extendedly dominated by Dutch Lipid.

Estimates using the three in 100 value of monogenic FH prevalence for the prevalence of VUS can be found in Table S5. Other than a very slight increase in expected total costs and ICERs, the change in prevalence of VUS did not impact the initial findings. FAMCAT2 continued to dominate the FAMCAT1 algorithm and cholesterol criteria, while it extendedly dominated DLCN, but not SB.

\section{Discussion}

We investigated the cost-effectiveness of potential case-finding criteria for identifying monogenic FH in primary care. Our findings suggest that two approaches, the FAMCAT2 algorithm and SB criteria, were preferable over the other three interventions. FAMCAT2 identified most cases of monogenic FH within our cohort, requiring the fewest number of genetic tests to find one monogenic FH case, and consequently having favourable ICERs. SB identified the most cases of monogenic FH; however, it required a much larger number of genetic tests to find one case and, thus, a large, expected cost per patient compared to the other interventions, with a corresponding large ICER when compared with FAMCAT2.

\subsection{Strengths}

This analysis was based on current relevant costs to the NHS of the note searching, clinician, and healthcare professional time, genetic and biochemical testing, and management costs. As such, it gives an accurate estimate of actual costs likely to be incurred in the use of these different algorithms in general practice in the UK. The modelling was based on data obtained from a representative group of general practices and included note searching from over 86,219 individuals. As such, it is likely to be directly relevant to methods for FH case finding in general practice in the UK as recommended by NICE guidelines [4].

\subsection{Limitations}

We only included a short time horizon, omitting potential long-term consequences that may occur from the treatment of patients with FH. FH is associated with long-term outcomes, such as premature heart attacks and heart disease, all of which can have a serious impact on the health and quality of life. Furthermore, treatment is relatively successful, and can mitigate most of the impacts of $\mathrm{FH}[6,25]$. The omission of the impacts of FH and the benefits of successful treatment suggests that we are conservatively estimating the cost-effectiveness of the different screening algorithms. To model long-term costeffectiveness would require additional data on quality of life, impact of treatment, and uptake of treatment, none of which were captured as part of the original study $[12,17]$. 
However, it has been estimated that over $80 \%$ of the lifetime treatment costs associated with FH are accrued within the first year of diagnosis [26]; therefore, there would be little impact on healthcare resources beyond a time horizon of 1 year.

This evaluation does not include any benefits or cases of FH identified through cascade testing. Cascade testing is important since $\mathrm{FH}$ is a monogenic disorder; hence, once one family member has been identified as having $\mathrm{FH}$, all first-degree relatives are at $50 \%$ chance of also having $\mathrm{FH}$ and can benefit from receiving appropriate treatments. Cascade testing has been shown to be both feasible, acceptable, and cost-effective [10,26-28]; therefore, it can be argued that the omission of the benefits from cascade testing will give conservative estimates for cost-effectiveness. However, the impact of cascade testing was considered out of scope for our evaluation, since the aim of the study was to identify the cost-effectiveness of index case identification. Since cascade testing has already been shown as cost-effective, then, once we have identified a cost-effective way of identifying index cases, we already know that cascade testing should be offered.

We assumed a worst-case scenario for intervention costs, in that all patients who are identified as being above risk consent to and complete a genetic test and attend any subsequent GP consultations if required. This could be considered unrealistic, as previous studies have shown that only $43 \%$ of patients with possible FH actually attended a GP consultation when informed they may be of risk of FH [29]. By using a worst-case scenario for resource use, we could be over-inflating the costs associated with each screening algorithm and potentially over-estimating the number of patients who are confirmed with FH. However, it is likely that loss to follow-up would be the same irrespective of which algorithm was used; therefore, the use of the worst-case scenario is unlikely to change the overall ranking of the algorithms.

The cohort study used specifically focuses on patients that already have a high recorded cholesterol level to inform the model inputs for the effectiveness of the different screening algorithms. This creates two issues for the evaluation. Firstly, we may not be estimating the true prevalence of monogenic $\mathrm{FH}$ within the population, since the algorithms only focus on those which report clinical features of FH which is a smaller population of those with monogenic FH. Secondly, since the study was non-random, there may be biases within the data that could influence our results. The group of patients was restricted to those with high cholesterol; thus, the interventions may have overestimated the number of patients who do not have a relevant mutation as being flagged as above risk by the casefinding criteria. Had the interventions been applied to a sample more representative of the general primary care population, the proportion of individuals with no relevant mutation being flagged as above risk may have been lower, reducing the number of genetic tests and the total expected cost per patient for each intervention. However, as demonstrated in the one-way sensitivity analysis, the overall finding of the FAMCAT2 algorithm and SB criteria being preferred over the other interventions did not change, suggesting that this may not have influence over the evaluation's findings.

\subsection{In Context with Other Work}

There are no known studies that evaluated different electronic screening criteria for index case identification of FH within primary care, preventing direct comparison. Crosland et al. evaluated several strategies for diagnosing FH within primary care amongst cascade patients [10], which included using both the DLCN and the SB criteria for index case identification, as well as a strategy of using a genetic test on its own. All three strategies were found to be cost-effective, and well below commonly accepted UK decision-making thresholds [30]. We also found the DLCN and SB criteria to be cost-effective; however, DLCN was outperformed by the FAMCAT2 algorithm. Therefore, it is likely that, had the FAMCAT2 algorithm been available at the time when Crosland et al. were conducting their evaluation, it too would have also been considered cost-effective. 


\subsection{Implications for Policy}

Our findings suggest that using electronic criteria to screen patients' electronic health records is a highly cost-effective approach for identifying index cases of FH within primary care. The use of the SB criteria yielded the most cases identified but required a large expenditure of healthcare resources. In contrast, while FAMCAT2 did not identify as many cases as SB, it was considerably cheaper and a good combination of sensitivity and specificity. While the other approaches had utility, they were dominated by FAMCAT2 as they required more resources to detect fewer or the same number of cases of $\mathrm{FH}$.

Supplementary Materials: The following supporting information can be downloaded at https: //www.mdpi.com/2075-4426/12/3/330/s1, Table S1: Key design criteria for economic model, Table S2: Model inputs for the decision tree, Table S3: Scenario analysis for different thresholds associated with FAMCAT1 and FAMCAT2 algorithms, Table S4: Results of scenario analysis for different thresholds associated with FAMCAT1 and FAMCAT2 algorithms, Table S5: Results of scenario analysis for a different proportion of patients who have VUS within the population (three in 100), Table S6: Sensitivity analysis of proportion of patients with no relevant mutation being identified as above risk by the algorithms, Table S7: Consolidated Health Economic Evaluation Reporting Standards (CHEERS) statement.

Author Contributions: Conceptualisation, N.Q., S.W., M.J. and K.P.; methodology, N.Q., S.W., M.J. and K.P.; validation, N.Q., K.P. and S.E.H.; formal analysis, M.J.; investigation, M.J.; writing—original draft preparation, M.J.; writing-review and editing, M.J., R.K.A., K.P., S.E.H., H.A.-H., S.W. and N.Q.; project administration, M.J.; funding acquisition, N.Q., K.P., S.W., M.J. and S.E.H. All authors have read and agreed to the published version of the manuscript.

Funding: This study/project is funded by the National Institute for Health Research (NIHR) School for Primary Care Research (project reference FR12-332). The views expressed are those of the authors and not necessarily those of the NIHR or the Department of Health and Social Care.

Institutional Review Board Statement: The study was sponsored by the University of Nottingham (sponsor reference: 16090), with approvals granted by the Health Research Authority (HRA, IRAS project ID: 213043) after ethics review by NRES Committee East Midlands (Reference: 16/EM/0461).

Informed Consent Statement: Not applicable.

Data Availability Statement: The data presented in this study are available in Supplementary Table S2.

Acknowledgments: The authors would like to thank members of the FAMCAT external study steering committee (Paul Roderick, Dermot Neely, Andrew Neil, Simon Williams) and patient representatives Phil Rowlands and Mark Fisher for their advice. The authors also thank the local lipidologists (Pankaj Gupta, Roger Stanworth) for their specialist input, as well as Tony Wierzbicki and Maggie Williams for reviewing genetic test results. S.E.H. acknowledges grants RG3008 and PG008/08 from the British Heart Foundation, and the support of the UCLH NIHR BRC. The FAMCAT study team acknowledges the support of the National Institute for Health Research Clinical Research Network (NIHR CRN). Lastly, the authors thank all the patients and primary care practices for their participation in this study.

Conflicts of Interest: N.Q. has received honoraria and travel costs for lectures from AMGEN and grants from National Institute for Health Research Health Technology Assessment Programme during the conduct of the study. S.W. reports personal fees from AMGEN, personal fees from Quealth Ltd. Outside the submitted work and was a member of Clinical Practice Research Datalink Independent Scientific Advisory Committee (ISAC). S.E.H. is the Medical Director of a UCL spin-out company StoreGene that offers to clinicians genetic testing for patients with FH. S.E.H. directs the UK Children's FH Register, which has been supported by a grant from Pfizer (24052829) given by the International Atherosclerosis Society, and has received honoraria for Advisory Board work with Novatis. K.P., M.J., R.K.A. and H.A.-H. declare no conflict of interests. 


\section{References}

1. Sharifi, M.; Futema, M.; Nair, D.; Humphries, S.E. Genetic Architecture of Familial Hypercholesterolaemia. Curr. Cardiol. Rep. 2017, 19, 44. [CrossRef] [PubMed]

2. Scientific Steering Committee on behalf of the Simon Broome Register Group. Risk of fatal coronary heart disease in familial hypercholesterolaemia. BMJ 1991, 303, 893-896. [CrossRef] [PubMed]

3. Neil, H.A.; Huxley, R.R.; Hawkins, M.M.; Durrington, P.N.; Betteridge, D.J.; Humphries, S.E. Comparison of the risk of fatal coronary heart disease in treated xanthomatous and non-xanthomatous heterozygous familial hypercholesterolaemia: A prospective registry study. Atherosclerosis 2003, 170, 73-78. [CrossRef]

4. National Institute for Health and Care Excellence. Familial Hypercholesterolaemia: Identification and Management: Clinical Guideline [CG71]; National Institute for Health and Care Excellence: London, UK, 2019.

5. Iyen, B.; Qureshi, N.; Weng, S.; Roderick, P.; Kai, J.; Capps, N.; Durrington, P.N.; McDowell, I.F.; Soran, H.; Neil, A.; et al. Sex differences in cardiovascular morbidity associated with familial hypercholesterolaemia: A retrospective cohort study of the UK Simon Broome register linked to national hospital records. Atherosclerosis 2020, 315, 131-137. [CrossRef] [PubMed]

6. Humphries, S.E.; Cooper, J.A.; Seed, M.; Capps, N.; Durrington, P.N.; Jones, B.; McDowell, I.F.W.; Soran, H.; Neil, H.A.W. Coronary heart disease mortality in treated familial hypercholesterolaemia: Update of the UK Simon Broome FH register. Atherosclerosis 2018, 274, 41-46. [CrossRef]

7. Wald, D.S.; Bestwick, J.P.; Morris, J.K.; Whyte, K.; Jenkins, L.; Wald, N.J. Child-Parent Familial Hypercholesterolemia Screening in Primary Care. N. Engl. J. Med. 2016, 375, 1628-1637. [CrossRef]

8. National Health Service. The NHS Long Term Plan; National Health Service: London, UK, 2019.

9. Maynard, A. Rationing health care: An exploration. Health Policy 1999, 49, 5-11. [CrossRef]

10. Crosland, P.; Maconachie, R.; Buckner, S.; McGuire, H.; Humphries, S.E.; Qureshi, N. Cost-utility analysis of searching electronic health records and cascade testing to identify and diagnose familial hypercholesterolaemia in England and Wales. Atherosclerosis 2018, 275, 80-87. [CrossRef]

11. Hendricks-Sturrup, R.M.; Lu, C.Y. Understanding Implementation Challenges to Genetic Testing for Familial Hypercholesterolemia in the United States. J. Pers. Med. 2019, 9, 9. [CrossRef]

12. Qureshi, N.; Akyea, R.K.; Dutton, B.; Leonardi-Bee, J.; Humphries, S.E.; Weng, S.; Kai, J. Comparing the performance of the novel FAMCAT algorithms and established case-finding criteria for familial hypercholesterolaemia in primary care. Open Heart 2021, 8, e001752. [CrossRef]

13. Roberts, M.; Russell, L.B.; Paltiel, A.D.; Chambers, M.; McEwan, P.; Krahn, M. Conceptualizing a model: A report of the ISPOR-SMDM Modeling Good Research Practices Task Force-2. Med. Decis. Mak. Int. J. Soc. Med. Decis. Mak. 2012, 32, 678-689. [CrossRef] [PubMed]

14. Caro, J.J.; Briggs, A.H.; Siebert, U.; Kuntz, K.M. Modeling good research practices-overview: A report of the ISPOR-SMDM Modeling Good Research Practices Task Force-1. Med. Decis. Mak. Int. J. Soc. Med. Decis. Mak. 2012, 32, 667-677. [CrossRef] [PubMed]

15. Weinstein, M.C.; O’Brien, B.; Hornberger, J.; Jackson, J.; Johannesson, M.; McCabe, C.; Luce, B.R. Principles of good practice for decision analytic modeling in health-care evaluation: Report of the ISPOR Task Force on Good Research Practices-Modeling Studies. Value Health 2003, 6, 9-17. [CrossRef] [PubMed]

16. Husereau, D.; Drummond, M.; Petrou, S.; Carswell, C.; Moher, D.; Greenberg, D.; Augustovski, F.; Briggs, A.H.; Mauskopf, J.; Loder, E. Consolidated Health Economic Evaluation Reporting Standards (CHEERS)—Explanation and Elaboration: A Report of the ISPOR Health Economic Evaluation Publication Guidelines Good Reporting Practices Task Force. Value Health 2013, 16, 231-250. [CrossRef] [PubMed]

17. Qureshi, N.; Akyea, R.K.; Dutton, B.; Humphries, S.E.; Abdul Hamid, H.; Condon, L.; Weng, S.F.; Kai, J. Case-finding and genetic testing for familial hypercholesterolaemia in primary care. Heart 2021, 107, 1928-1930. [CrossRef]

18. Mach, F.; Baigent, C.; Catapano, A.L.; Koskinas, K.C.; Casula, M.; Badimon, L.; Chapman, M.J.; De Backer, G.G.; Delgado, V.; Ference, B.A.; et al. 2019 ESC/EAS Guidelines for the management of dyslipidaemias: Lipid modification to reduce cardiovascular risk: The Task Force for the management of dyslipidaemias of the European Society of Cardiology (ESC) and European Atherosclerosis Society (EAS). Eur. Heart J. 2019, 41, 111-188. [CrossRef]

19. Weng, S.; Kai, J.; Akyea, R.; Qureshi, N. Detection of familial hypercholesterolaemia: External validation of the FAMCAT clinical case-finding algorithm to identify patients in primary care. Lancet Public Health 2019, 4, e256-e264. [CrossRef]

20. Brennan, A.; Chick, S.E.; Davies, R. A taxonomy of model structures for economic evaluation of health technologies. Health Econ. 2006, 15, 1295-1310. [CrossRef]

21. Drummond, M.F.; Sculpher, M.J.; Torrance, G.W.; O'Brien, B.J.; Stoddart, G.L. Methods for the Economic Evaluation of Health Care Programmes, 3rd ed.; Oxford University Press: Oxford, UK, 2005.

22. Briggs, A.; Sculpher, M.J.; Claxton, K. Decision Modelling for Health Economic Evaluation, 1st ed.; Oxford University Press: Oxford, UK, 2006.

23. Ausvet. Confidence Limits for a Proportion. Available online: https:/ / epitools.ausvet.com.au/ ciproportion (accessed on 13 April 2021).

24. Haralambos, K.; Humphries, S.E.; Whitmore, J.; Datta, D.; Cather, M.; Miedzybrodzka, Z.; Breen, J.; Gritzmacher, L.; Hamlen, A.; Potter, A.; et al. Familial hypercholesterolaemia (fh) genetic testing in the UK. Atheroscler. Suppl. 2018, 34, e4. [CrossRef] 
25. Duell, P.B.; Gidding, S.S.; Andersen, R.L.; Knickelbine, T.; Anderson, L.; Gianos, E.; Shrader, P.; Kindt, I.; O’Brien, E.C.; McCann, D.; et al. Longitudinal low density lipoprotein cholesterol goal achievement and cardiovascular outcomes among adult patients with familial hypercholesterolemia: The CASCADE FH registry. Atherosclerosis 2019, 289, 85-93. [CrossRef]

26. Kerr, M.; Pears, R.; Miedzybrodzka, Z.; Haralambos, K.; Cather, M.; Watson, M.; Humphries, S.E. Cost effectiveness of cascade testing for familial hypercholesterolaemia, based on data from familial hypercholesterolaemia services in the UK. Eur. Heart J. 2017, 38, 1832-1839. [CrossRef] [PubMed]

27. Knowles, J.W.; Rader, D.J.; Khoury, M.J. Cascade Screening for Familial Hypercholesterolemia and the Use of Genetic Testing. JAMA 2017, 318, 381-382. [CrossRef] [PubMed]

28. Nherera, L.; Marks, D.; Minhas, R.; Thorogood, M.; Humphries, S.E. Probabilistic cost-effectiveness analysis of cascade screening for familial hypercholesterolaemia using alternative diagnostic and identification strategies. Heart 2011, 97, 1175-1181. [CrossRef] [PubMed]

29. Qureshi, N.; Weng, S.; Tranter, J.; El-Kadiki, A.; Kai, J. Feasibility of improving identification of familial hypercholesterolaemia in general practice: Intervention development study. BMJ Open 2016, 6, e011734. [CrossRef]

30. Claxton, K.; Martin, S.; Soares, M.; Rice, N.; Spackman, E.; Hinde, S.; Devlin, N.; Smith, P.C.; Sculpher, M. Methods for the estimation of the National Institute for Health and Care Excellence cost-effectiveness threshold. Health Technol. Assess. 2015, 19, 5-6. [CrossRef] 